\title{
A shared subunit belongs to the eukaryotic core RNA polymerase
}

\author{
Martin Lanzendörfer, Amke Smid, Corinne Klinger, ${ }^{1}$ Patrick Schultz, ${ }^{1}$ André Sentenac, \\ Christophe Carles, ${ }^{2}$ and Michel Riva
}

Service de Biochimie et de Génétique Moléculaire, CEA/Saclay, F-91191 Gif sur Yvette CEDEX, France; ${ }^{1}$ Institut de Génétique et de Biologie Moléculaire et Cellulaire 1, BP163, F-67404 Illkirch CEDEX, France

The yeast RNA polymerase $I$ is a multimeric complex composed of 14 distinct subunits, 5 of which are shared by the three forms of nuclear RNA polymerase. The reasons for this structural complexity are still largely unknown. Isolation of an inactive form of RNA Pol I lacking the A43, ABC23, and A14 subunits (RNA Pol I $\Delta)$ allowed us to investigate the function of the shared subunit $\mathrm{ABC} 23$ by in vitro reconstitution experiments. Addition of recombinant ABC23 alone to the RNA Pol I $\Delta$ reactivated the enzyme to up to $50 \%$ of the wild-type enzyme activity. The recombinant subunit was stably and stoichiometrically reassociated within the enzymatic complex. ABC23 was found to be required for the formation of the first phosphodiester bond, but it was not involved in DNA binding by RNA Pol I, as shown by gel retardation and surface plasmon resonance experiments, and did not recycle during transcription. Electron microscopic visualization and electrophoretic analysis of the subunit depleted and reactivated forms of the enzyme indicate that binding of ABC23 caused a major conformational change leading to a transcriptionally competent enzyme. Altogether, our results demonstrate that the $\mathrm{ABC} 23$ subunit is required for the structural and functional integrity of RNA Pol $I$ and thus should be considered as part of the core enzyme.

[Key Words: Saccharomyces cerevisiae; RNA polymerase I; ABC23 subunit; in vitro reconstitution]

Received January 13, 1997; revised version accepted March 14, 1997.

As for all eukaryotes, yeast contains three nuclear RNA polymerases (Sentenac 1985). RNA polymerase I specifically transcribes the rDNA genes, RNA Pol II is mainly responsible for transcription of genes encoding mRNA, and RNA Pol III transcribes the genes encoding the small, stable, ribosomal 5S RNA and transfer RNAs and some stable nontranslated RNAs involved in RNA maturation. Each enzyme is composed of two large polypeptides, structurally and functionally homologous to the $\beta^{\prime}$ and $\beta$ subunits of the eubacterial RNA polymerase, associated with $10-15$ smaller subunits. Five subunits (ABC27, $\mathrm{ABC} 23, \mathrm{ABC} 14.5, \mathrm{ABC} 10 \alpha$, and $\mathrm{ABC} 10 \beta$ ) (Buhler et al. 1976b; Woychik et al. 1990; Carles et al. 1991) are common to the three RNA polymerases. In addition, RNA Pol I and Pol III share two subunits, AC40 and AC19 (Mann et al. 1987; Dequard-Chablat et al. 1991). All of the common subunits are essential for cell viability and are of special interest, as they may play an important role in the basic function of the enzymes or in the coordinated regulation of the different polymerases. Phylogenetic studies of these subunits indicated that $\mathrm{ABC} 14.5$ and $\mathrm{ABC} 10 \alpha$ have no known homolog in the archeal RNA polymerase (Bult et al. 1996) and thus may be typically eukaryotic, whereas $\mathrm{ABC} 27, \mathrm{ABC} 23$, and

\footnotetext{
${ }^{2}$ Corresponding author.
}

E-MAIL biochimi@jonas.saclay.cea.fr; FAX 33169084712.
$\mathrm{ABC} 10 \beta$ are related to bona fide subunits of the archeal RNA polymerase (Langer et al. 1995). In addition, $\mathrm{ABC} 27, \mathrm{ABC} 23$, and $\mathrm{ABC} 14.5$ are immunologically conserved in Drosophila melanogaster and to a lesser extent in mammals (Huet et al. 1982). Recent genetic studies demonstrated that four of the yeast shared subunits $(\mathrm{ABC} 23, \mathrm{ABC} 14.5, \mathrm{ABC} 10 \alpha$, and $\mathrm{ABC10} \beta)$ are in vivo functionally interchangeable with their human homologs, demonstrating a remarkable structural and functional conservation of these subunits from Saccharomyces cerevisiae to Homo sapiens (McKune et al. 1995; Shpakovski et al. 1995).

Nevertheless, even though the conservation of the shared subunits through evolution is well documented, their role in the transcription process is still elusive. Among these subunits, $\mathrm{ABC} 23$ is particularly interesting, as antibodies raised against this subunit completely inhibit the activity of RNA Pol I, Pol II, and Pol III (Buhler et al. 1980; Bréant et al. 1983b; Huet et al. 1985b). It has been suggested that $\mathrm{ABC} 23$ could be involved in the interaction with the template after observing that this inhibition was relieved by the preincubation of the enzyme with DNA (Bréant et al. 1983b; Huet et al. $1985 \mathrm{~b}$ ). In addition, the elongation factor P37 (SII) delays the inhibitory effect of anti-ABC23 antibodies both on RNA Pol I and Pol II (Sawadogo et al. 1980). It was therefore possible that the P37 protein contacts this subunit, at least partly, in both enzymes. Studies on post-trans- 
lational modifications of yeast RNA polymerases demonstrated that $\mathrm{ABC} 23$ is the unique common subunit that is phosphorylated in vivo in the three forms of enzyme (Bell et al. 1976, 1977; Buhler et al. 1976a). Its human counterpart is also phosphorylated in vivo (M. Vigneron, pers. comm.). Nevertheless, the role of this post-translational modification has to be determined. In addition, a genetic interaction has been reported between $\mathrm{ABC} 23$ and $\mathrm{B} 220$, the largest subunit of RNA Pol II (Archambault et al. 1990). Recently, mutational analysis of $R P B 6$ suggested that $\mathrm{ABC} 23$ is essential for the assembly of yeast RNA Pol I and Pol II and for the stability of the largest subunits of these enzymes (Nouraini et al. 1996).

Many basic questions related to the minimal structure of the eukaryotic core RNA polymerase need to be addressed. Is $\mathrm{ABC} 23$ essential for the structural or functional integrity of the RNA polymerases? Is the function of this subunit identical in the three enzymes? Is ABC23 part of the core enzyme? So far, and in contrast with the Escherichia coli RNA polymerase, no successful reconstitution of an active eukaryotic RNA polymerase from its isolated subunits has been achieved. In this paper we describe the purification and characterization of an inactive form of RNA Pol I lacking the subunits A43, $\mathrm{ABC} 23$, and Al4 (RNA Pol I $\Delta$ ) and its complementation by recombinant $\mathrm{ABC} 23$ subunit (rABC23). We demonstrate that $\mathrm{rABC} 23$ associates stoichiometrically and stably to RNA Pol I $\Delta$ in the absence of subunits Al4 and A43 and causes a major conformational change in the enzyme. The reconstituted enzyme (RNA Pol I $\Delta+23$ ) was active in a nonspecific transcription assay. Altogether, our data indicate that subunit $\mathrm{ABC} 23$, but not A14 or A43, is required to form a transcriptionally competent enzyme.

\section{Results}

RNA Pol I $\Delta$ is an incomplete and inactive form of $R N A$

Purification of RNA Pol I by the standard procedure from a rpa14::URA3 mutant containing a disruption of the Al4 subunit gene yielded an inactive form of enzyme (RNA Pol I $\Delta$ ) lacking the A43, ABC23, and A14 subunits (Smid et al. 1995). Moreover, RNA Pol I $\Delta$ could be recovered at only $20 \%$ yield compared to the wild-type enzyme. Because Western blot analysis with anti-RNA Pol I antibodies indicated that the amount of enzyme was identical in extracts from wild-type or rpa14::URA3 cells (Smid et al. 1995), we concluded that the low yield was attributable to the purification procedure itself and not to a lower amount of RNA Pol I assembled in the mutant strain. Therefore, we developed a new purification procedure to purify RNA Pol I $\Delta$ from the rpa14::URA3 strain to undertake in vitro reconstitution experiments. Briefly, proteins from a crude extract were adsorbed on phosphocellulose at low ionic strength 150 $\mathrm{mm}$ ammonium sulfatel, eluted at $400 \mathrm{~mm}$ ammonium sulfate, and loaded on a heparin column. The column was developed with a salt gradient, and the elution fractions containing RNA Pol I $\Delta$, as detected by Western blotting, were further chromatographed on a DEAESephadex column. Protein fractions containing RNA Pol I $\Delta$ were pooled and sedimented through a glycerol gradient (see Material and Methods). Analysis of the subunit composition of RNA Pol I $\Delta$ by SDS-PAGE showed that the enzyme was highly purified and lacked subunits A43, ABC23, and A14 (Fig. 1, lane 2). The stoichiometry of the other subunits assembled in the RNA Pol I $\Delta$ was the same as for the wild-type enzyme (Fig 1, lanes 1,2). As mentioned previously, purified RNA Pol I $\Delta$ was not active in an in vitro nonspecific transcription assay. However, depending on the preparations of RNA Pol I $\Delta$, a small residual activity was observed corresponding up to $5 \%$ that of the wild-type enzyme. Western blot analysis revealed the presence of low amounts of $A B C 23$ subunit in the slightly active preparations (data not shown). On the other hand, subunit A43 was never detected in any preparation, and no significant variation in the content of the other subunits was observed. Therefore, we assumed that the low activity of some RNA Pol I $\Delta$ preparations was attributable to the presence of residual $\mathrm{ABC} 23$ subunit. Interestingly, this observation suggested

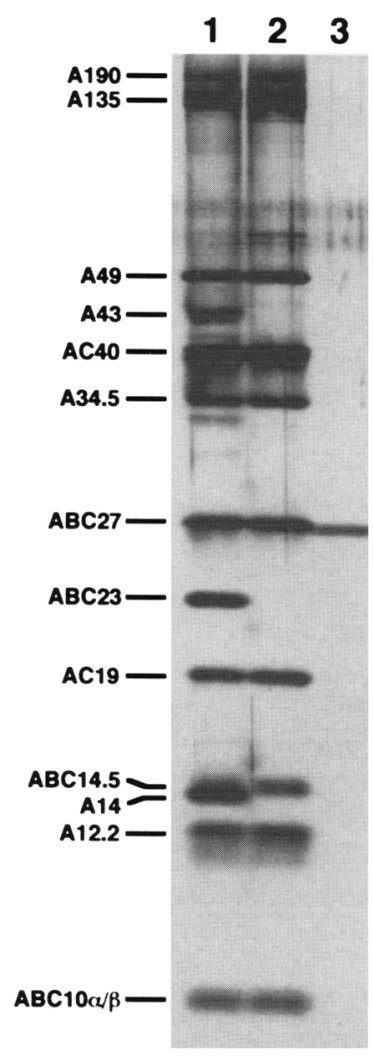

Figure 1. RNA Pol I $\Delta$ lacks subunits $A 43, \mathrm{ABC} 23$, and $\mathrm{A} 14$. Purified wild-type RNA Pol I (lane 1), RNA Pol I $\Delta$ (lane 2), and rABC23 (lane 3) were analyzed by electrophoresis in a $13 \%$ polyacrylamide gel in the presence of SDS and silver stained. The RNA Pol I subunits are indicated. 
that among the three missing subunits, $\mathrm{ABC} 23$, when associated with RNA Pol I $\Delta$, could at least partially restore the transcriptional activity of RNA Pol I $\Delta$ in a non-specific in vitro assay. To address this issue, we performed in vitro reconstitution experiments with purified RNA Pol I $\Delta$ and recombinant $\mathrm{ABC} 23$ subunit (rABC23).

\section{The tagged $A B C 23$ subunit is functional and stably} associated with RNA Pol I in vivo

Recombinant $\mathrm{ABC} 23$ subunit was overexpressed in a yeast strain rather than in $E$. coli because the yeast polypeptide is phosphorylated in vivo. Whether this posttranslational modification has a structural or functional role remains to be determined. For a convenient purification and identification of the recombinant subunit, a tag of six consecutive histidine residues and an HA epitope were introduced at the amino terminus of the ABC23 subunit (see Material and Methods). The modified gene was then introduced into a haploid yeast strain that contained a chromosomal-disrupted RPB6 gene and an autonomously replicating plasmid carrying the $R P B 6$ allele. After plasmid shuffling (Mann et al. 1987), cells having lost the resident plasmid showed a wild-type phenotype. This demonstrated that the adjunction of two tags at the amino terminus of the $\mathrm{ABC} 23$ subunit did not interfere with its structure and/or its function in vivo. To verify that the tagged $\mathrm{ABC} 23$ subunit was stably associated with RNA Pol I, we purified the enzyme from the mutant yeast strain overexpressing the tagged ABC23 subunit. The RNA Pol I obtained had the same specific activity as the wild-type enzyme and the usual subunit content, in particular, with respect to the stoichiometry of rABC23 (data not shown). This demonstated that $\mathrm{rABC} 23$ was stably incorporated within RNA Pol I and was therefore suitable for reconstitution studies with RNA Pol I $\Delta$.

Recombinant $\mathrm{ABC} 23$ was purified by two affinity chromatography steps as described in Material and Methods. The recombinant subunit was detected by Western blotting analysis with anti-ABC23 or anti-HA antibodies. Silver staining of $\mathrm{rABC} 23$ indicated that the preparation was homogeneous (Fig. 1, lane 3). Note that as expected, the electrophoretic mobility of the tagged, recombinant $\mathrm{rABC} 23$ was lower than the mobility of the wild-type subunit $\mathrm{rABC} 23$ migrating just above or at the level of the $A B C 27$ subunit, depending on the electrophoretic conditions (Fig 1, cf. lanes 2 and 3). Obtention of pure RNA Pol I $\Delta$ and $\mathrm{rABC} 23$ prompted us to perform in vitro reconstitution experiments.

\section{Purified $r A B C 23$ restores the basal activity of RNA Pol I $\Delta$}

To assemble rABC23 into inactive RNA Pol I $\Delta$, we first used the conditions described by Lanzendörfer et al. (1994) to successfully reconstitute an active archaeal RNA polymerase from its individual subunits. A twofold molar excess of $\mathrm{rABC} 23$ was incubated with RNA Pol I $\Delta$ for $20-30 \mathrm{hr}$ at $15^{\circ} \mathrm{C}$ in the presence of $40 \%$ glycerol, and the activity of the enzyme was determined using poly $[\mathrm{d}(\mathrm{A}-\mathrm{T})]$ as a template. When compared with the specific activity of purified RNA Pol I $\Delta$ incubated under the same conditions without $\mathrm{rABC} 23$, a strong activation was observed when RNA Pol I $\Delta$ was preincubated with the recombinant subunit. The maximal level of reactivation varied from $20 \%$ to $50 \%$, depending on the RNA Pol I $\Delta$ preparation with an average of $30 \%$. As expected, $\mathrm{rABC} 23$ alone did not exhibit any transcriptional activity, and its addition to wild-type RNA Pol I did not stimulate the enzyme activity. We noticed that reactivation was more effective when the enzyme was prepared freshly: After storing RNA Pol I $\Delta$ at $-80^{\circ} \mathrm{C}$ for several weeks, a reduced reconstitution efficiency was observed. This suggested that purified RNA Pol I $\Delta$ was less stable than RNA Pol I. The loss of additional subunits might prevent the reactivation of RNA Pol I $\Delta$. During the purification of RNA Pol I $\Delta$, we detected a minor form of RNA Pol I, missing A49, A43, A34,5, $A B C 23$, and $A 14$ subunits, which could not be reactivated by $\mathrm{rABC} 23$.

To explore the time course of the reactivation process, the same experiment was performed at $22^{\circ} \mathrm{C}$ with varying preincubation times. The same level of reactivation $(30 \%)$ of RNA Pol I $\Delta$ was obtained after $15 \mathrm{~min}, 1 \mathrm{hr}$, or $30 \mathrm{hr}$ of preincubation. Surprisingly, with very short preincubation times (10 sec or $1 \mathrm{~min})$ or even without a preincubation step (i.e., RNA Pol I $\Delta$ and $\mathrm{rABC} 23$ were directly added to the reaction mixture in the presence of the template and the nucleotides for $30 \mathrm{~min}$ at $30^{\circ} \mathrm{C}$ ), a lower but significant reactivation $(20 \%)$ was observed. This demonstrated that the activation of RNA Pol I $\Delta$ by $\mathrm{rABC} 23$ is a rapid reaction that can occur in the presence of the template and the nucleotides. Furthermore, the reaction seemed to be relatively insensitive to the ionic strength, as the presence of different salt concentrations (from 0 to $300 \mathrm{~mm} \mathrm{KCl}$ and 0 to $50 \mathrm{~mm}$ potassium glutamate) during the preincubation step $\left(1 \mathrm{hr}, 22^{\circ} \mathrm{C}\right)$ had no effect on the activation of RNA Pol I $\Delta$ by rABC23. Finally, to demonstrate further that the transcriptional reactivation of RNA Pol I $\Delta$ was correlated with the presence of $\mathrm{rABC} 23$, increasing amounts of the subunit were preincubated with the same amount of RNA Pol I $\Delta$ during $20 \mathrm{~min}$ at $22^{\circ} \mathrm{C}$ and transcriptional reactivation was determined further. A constant increase of reactivation was observed with increasing amounts of $\mathrm{rABC} 23$ until a plateau was reached (Fig. 2). The maximal reactivation was obtained with approximately an equimolar amount of rABC23 and RNA Pol I $\Delta$ and corresponded to $30 \%-$ $35 \%$ of the activity of the wild-type enzyme. These data demonstrated that $\mathrm{rABC} 23$ was responsible for the reactivation of RNA Pol I $\Delta$ and suggested that the free subunit stably reassociated with the enzymatic complex.

rABC23 associates stably and stoichiometrically with RNA Pol I $\triangle$

The physical association of $\mathrm{rABC} 23$ with RNA Pol I $\Delta$ was examined by gel filtration chromatography on a Superose 12 PC SMART column (Pharmacia). Control ex- 


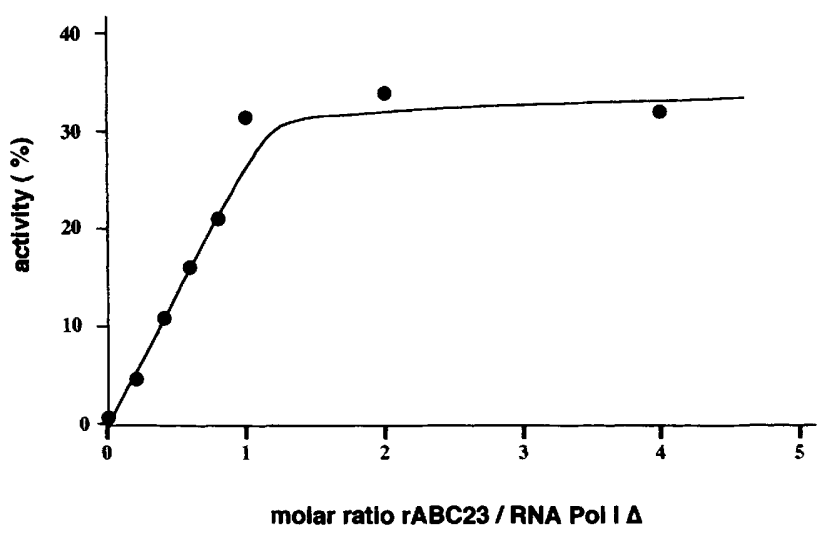

Figure 2. $\mathrm{rABC} 23$ is necessary and sufficient to reactivate RNA Pol I $\Delta$. RNA Pol I $\Delta$ was incubated with increasing amounts of $\mathrm{rABC} 23$, and the activity of the reconstituted enzyme was determined in a nonspecific transcription assay using poly[d(A-T)] as template. The activity recovered was expressed as the percent of activity of the same amount of wild-type RNA Pol I.

periments with RNA Pol I, RNA Pol I $\Delta$, or rABC23 showed that because of their large difference in size, RNA polymerases and $\mathrm{rABC} 23$ were eluted in distinct elution volumes $(0.95$ and $1.5 \mathrm{ml}$, respectively). When rABC23 was chromatographed alone, no trace of the subunit could be detected by Western blot analysis in the fractions corresponding to the elution volume of the RNA polymerase (data not shown). In the experiment shown in Figure 3, RNA Pol I $\Delta$ was incubated for $1 \mathrm{hr}$ at $22^{\circ} \mathrm{C}$ with a twofold molar excess of $\mathrm{rABC} 23$, and the proteins were chromatographed on a Superose 12 PC SMART column. The protein-containing fractions were then analyzed by Western blotting using anti-RNA Pol I antibodies. Figure 3 shows that $\mathrm{rABC} 23$ was present in the fractions containing RNA Pol I $\Delta$ (lanes 9-17) and in the fractions corresponding to free $\mathrm{rABC} 23$ (lanes 24,25). This observation was confirmed by Western blot analysis with anti-ABC23 antibodies (data not shown). Altogether, these results indicated clearly that $\mathrm{rABC} 23$ was stably reassociated with the RNA Pol I $\Delta$ complex leading to a novel form of RNA Pol I called RNA Pol I $\Delta+23$. Moreover, the stoichiometry of $\mathrm{rABC} 23$ within RNA Pol I $\Delta+23$ and that of $A B C 23$ in wild-type RNA Pol I were identical (data not shown). This indicated that $\mathrm{rABC} 23$ was quantitatively reassociated, although the activity of RNA Pol I $\Delta+23$ purified by gel permeation chromatography was only one-third that of the wild-type enzyme. Therefore, this partial reactivation was not related to a substoichiometric association of $\mathrm{rABC} 23$ to RNA Pol I $\Delta$.

Once assembled in RNA Pol I, ABC23 does not exchange with free $\mathrm{r} A B C 23$

As shown in Figure 2, rABC23 bound RNA Pol I $\Delta$ very rapidly. This is striking, as the reconstitution of multimeric complexes from their components is usually slow. For example, reconstitution of the eubacterial core RNA polymerase from subunits $\alpha, \beta$, and $\beta^{\prime}$ is a time-consuming process that requires several hours (Tang et al. 1996). On the other hand, the binding of $\sigma$ factor to the $E$. coli RNA polymerase to generate the holoenzyme is completed in $<1 \mathrm{hr}$ (Tang et al. 1996). The similar association of $\mathrm{rABC} 23$ and $\sigma$ factor prompted us to examine whether $\mathrm{ABC} 23$ might recycle during transcription as does $\sigma$ factor. To address this question, we incubated purified wildtype RNA Pol I with a fivefold molar excess of tagged, recombinant $\mathrm{ABC} 23$ for $30 \mathrm{~min}$ in the presence or in the absence of DNA template and nucleotides. Reaction mixtures were then chromatographed on a gel permeation column, and the amount of tagged $\mathrm{rABC} 23$ incorporated in the wild-type RNA polymerase was monitored after Western blot analysis of the enzyme fractions with anti-ABC23 IgG. Under both conditions (i.e., with or without transcription), the same result was obtained: $A B C 23$ assembled in vivo did not exchange with the free subunit. ABC23 did not behave like $\sigma$ factor. Next, we wanted to determine which transcriptional step was affected by RNA Pol I $\Delta$.

\section{$A B C 23$ is required at an early step of the transcriptional process}

Transcription can be divided schematically into several major steps: enzyme-DNA binding, initiation, elongation, and termination. Determination of the steps that are defective in attempted transcription by RNA Pol I $\Delta$ would highlight the function of the $\mathrm{ABC} 23$ subunit. Be-

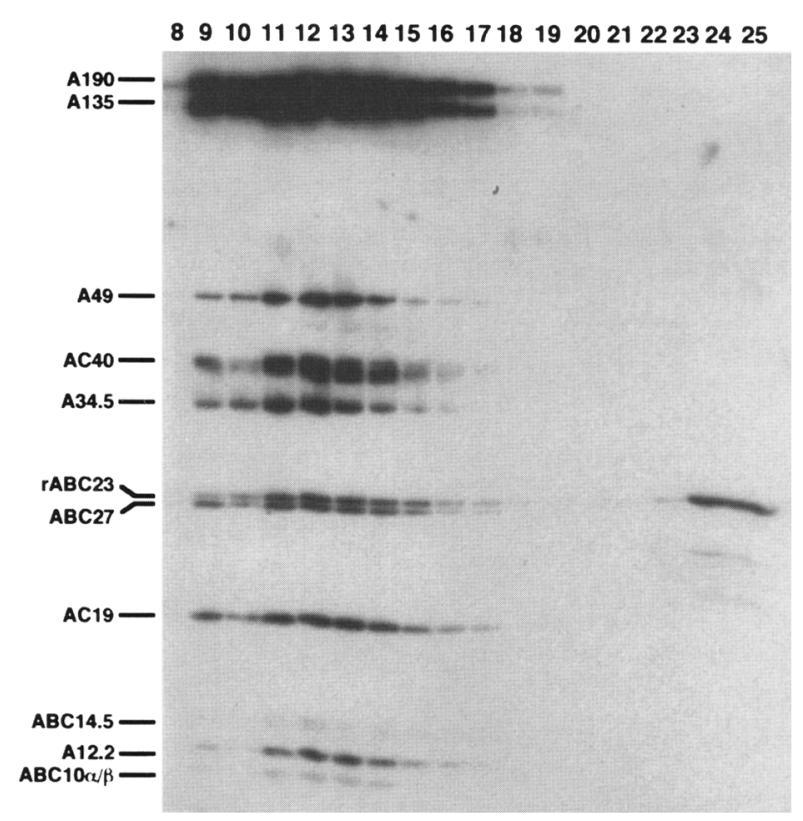

Figure 3. $\mathrm{rABC} 23$ is stably and stoichiometrically bound to RNA Pol I $\Delta$. RNA Pol I $\Delta$ was incubated with a twofold molar excess of $\mathrm{rABC} 23$ and subjected further to gel filtration chromatography on a Superose 12 PC SMART column. Proteins contained in fractions 8-25 were analyzed by Western blotting with anti-RNA Pol I antibodies. RNA Pol I subunits are indicated. 


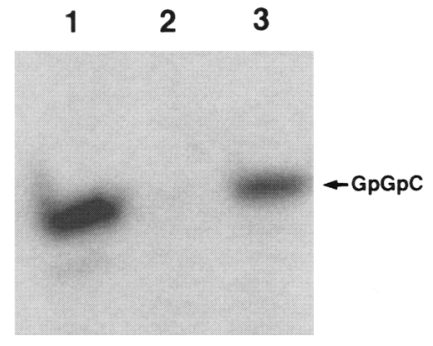

Figure 4. RNA Pol I $\Delta$ is affected in an early step of the transcription process. Synthesis of a single phosphodiester bond by RNA Pol I and RNA Pol I $\Delta$ was compared. RNA Pol I synthesizes only the trinucleotide $\mathrm{GpGpC}$ in the presence of CTP when transcription is performed with a dC-tailed oligonucleotide template and the dinucleotide primer GpG. The amount of trinucleotide synthesized by RNA Pol I (lane 1), RNA Pol I $\Delta$ (lane 2), and RNA Pol I $\Delta+23$ (lane 3) was quantified with a PhosphorImager after separation of the transcript from free $\left[\alpha-{ }^{32} \mathrm{P}\right]$ CTP by gel electrophoresis. The autoradiograph is shown.

cause, in the former experiments, the activity of RNA Pol I $\Delta$ was determined using an assay monitoring the synthesis of long, TCA-precipitable trancripts on a poly[d(A-T)] template, we investigated whether the RNA Pol I $\Delta$ was able to catalyze at least one phosphodiester bond or to perform abortive initiation. For this purpose, transcription of a short $(40 \mathrm{bp})$ synthetic doublestranded, dC-tailed DNA template was analyzed. This template was incubated in the presence of all four nucleotides with RNA Pol I, RNA Pol I $\Delta$, or RNA Pol I $\Delta+23$. Short RNA products were separated by electrophoresis and quantified. RNA Pol I $\Delta$ was unable to synthesize detectable levels of short or abortive transcripts, whereas RNA Pol I $\Delta+23$ was again $30 \%$ as active as the wild-type enzyme in synthesizing a 37-bp RNA product. We then examined the ability of RNA Pol I $\Delta$ to catalyze the formation of a single phosphodiester bond. The same dC-tailed template was incubated with RNA Pol I, RNA Pol I $\Delta$ or RNA Pol I $\Delta+23$ in the presence of the initiator dinucleotide $\mathrm{pGpG}$ and radiolabeled CTP. Under such transcription conditions, RNA Pol I only synthesized the trinucleotide GpGpC. The synthesized trinucleotide was separated by electrophoresis and quantified with a PhosphorImager (Fig. 4). The transcriptional activity of RNA Pol I $\Delta$ and RNA Pol I $\Delta+23$ was $0 \%$ and $30 \%$, respectively, when compared to the activity of the wild-type enzyme. Identical results were obtained in the presence of heparin (data not shown). It thus appears that the inactive form was affected at a very early step of the transcriptional process.

RNA Pol I $\Delta$ is not affected in the binding of the DNA template

Because RNA Pol I $\Delta$ was not able to catalyze the formation of a single phosphodiester bond, we checked whether the enzyme could still bind the DNA template. The affinity of RNA Pol I, RNA Pol I $\Delta$, and RNA Pol I
$\Delta+23$ for DNA was examined using an electrophoretic mobility shift assay with the same dC-tailed template as a probe. DNA-protein complexes were formed when RNA Pol I, RNA Pol I $\Delta$, and RNA Pol I $\Delta+23$ were incubated with the labeled template (Fig. 5). In each case, the amount of the free DNA band decreased and slow migrating complexes were observed. With RNA Pol I or with RNA Pol I $\Delta+23$, the fast-migrating complex was predominant (Fig. 5, lanes 2,4), whereas with RNA Pol I $\Delta$, this complex was represented less and larger complexes accumulated that barely entered the gel (Fig. 5, lane 3). Note that no protein-DNA complex was detected when the $\mathrm{rABC} 23$ subunit was incubated alone with the probe (Fig. 5, lane 5). Despite the mobility differences of the DNA-RNA polymerase complexes, quantification of free DNA with the PhosphorImager indicated that the same amount of template was complexed to each form of enzyme. This result suggested that RNA Pol I, RNA Pol I $\Delta$, and RNA Pol I $\Delta+23$ had the same affinity for the DNA template. This conclusion was confirmed by the determination of the association constant $\left(K_{\mathrm{a}}\right)$, the dissociation constant $\left(K_{\mathrm{d}}\right)$, and the affinity constant $\left(K_{\mathrm{A}}\right)$ of RNA Pol I and RNA Pol I $\Delta$ for the same oligonucleotidic DNA template, using surface plasmon resonance (SPR). SPR detects small local changes in refractive index linked directly to alterations in ligand concentration at a binding surface and was ideally suited for measuring binding affinities between DNA immobilized on a surface and proteins in solution or vice versa. The biotinylated template was immobilized on a streptavidin-pretreated sensor chip and incubated with different concentrations of wild-type RNA Pol I or RNA Pol I $\Delta$. Very similiar $K_{\mathrm{A}}$ values of $4.0 \times 10^{8}$ and $4.4 \times 10^{8}$ were calculated for RNA Pol I $\Delta$ and RNA Pol I, respectively.

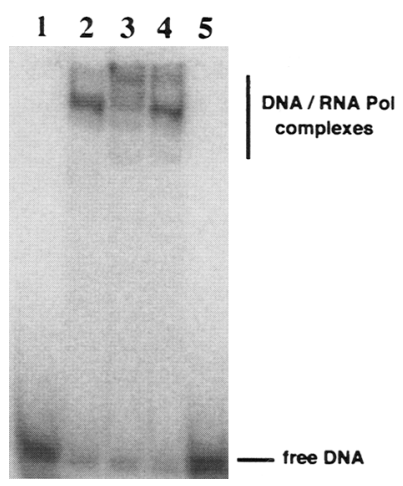

Figure 5. The $\mathrm{ABC} 23$ subunit does not participate in the binding of RNA Pol I to DNA. Interaction of RNA Pol I (lane 2), RNA Pol I $\Delta$ (lane 3), RNA Pol I $\Delta+23$ (lane 4), or rABC23 (lane 5) with a dC-tailed oligonucleotide was analyzed by a gel retardation assay. One picomole of the different proteins was incubated with a twofold molar excess of ${ }^{32} \mathrm{P}$-labeled oligonucleotide. The protein-DNA complexes were separated from free DNA by electrophoresis on a $5 \%$ polyacrylamide gel. Autoradiography of the gel is shown. (Lane 1) The free DNA probe alone. The positions of the free DNA probe and of the protein-DNA complexes are indicated. 
These data demonstrated that $\mathrm{ABC} 23$ was not involved significantly in the binding of RNA Pol I to the DNA template. In view of the different migration of the enzyme-DNA complexes, it was possible that binding of ABC23 to RNA Pol I $\Delta$ induced a large conformational change of the enzyme conferring a three-dimensional structure competent for transcription. However, no significant difference in the elution volumes of RNA Pol I and RNA Pol I $\Delta$ was observed by gel permeation on a Superose 12 PC column (data not shown). To reveal more discrete structural changes, the structure of the native and mutant RNA Pol I was then investigated by electron microscopy.

\section{Electron microscopic observation of native and mutant RNA Pol I}

When observed by electron microscopy, native RNA polymerase molecules appeared as a mixture of dimeric and monomeric forms (Klinger et al. 1996). The dimeric form was absent in RNA Pol I $\Delta$ preparations, and the dimers did not reconstitute upon addition of $\mathrm{rABC} 23$, suggesting that the loss of subunits A14 and/or A43 probably interfered with dimerization. By visual inspection, monomers of the mutant and the wild-type enzyme were indistinguishable except for a more pronounced tendency to aggregation in the case of the mutant enzyme. This observation could be correlated with the low stability of RNA Pol I $\Delta$ upon conservation at $-80^{\circ} \mathrm{C}$.

To detect structural changes that could account for the altered catalytic properties of the mutant enzyme, images were recorded and analyzed for each enzyme preparation. To produce a statistically significant set of structural data, average images were calculated for two different orientations of the monomeric enzyme that corresponded to upside-down positions of the enzyme (Fig. 6, projections 1 and 2). The most striking difference was the disappearance in RNA Pol I $\Delta$ of an elongated stalk that was shown previously to be located at the dimerization interface (Fig. 6, arrow). This difference (labeled a in Fig. 6) was found at equivalent positions in both enzyme views, and corresponded probably to the loss of the three subunits in the RNA Pol I $\Delta$ complex. The size of density a was reduced slightly upon addition of subunit $\mathrm{rABC} 23$, but the stalk was not restored suggesting that subunits A43 and/or A14 contribute to this structure.

Unexpectedly, additional densities (labeled b and $\mathrm{c}$ in Fig. 6) appeared in RNA Pol I $\Delta$. These densities were observed reproducibly at equivalent positions in both enzyme views which constituted two independent data sets. It can thus be excluded that these differences arose from a different orientation of RNA Pol I $\Delta$. Because RNA Pol I $\Delta$ lacked three subunits, these differences most probably reflect modifications in the internal density distribution of the complex. These results thus imply that RNA Pol I $\Delta$ had a different conformation than the native enzyme. The negative density $b$ was located slightly above the positive difference a and corresponded in the three-dimensional model shown in Figure $7 \mathrm{C}$ to

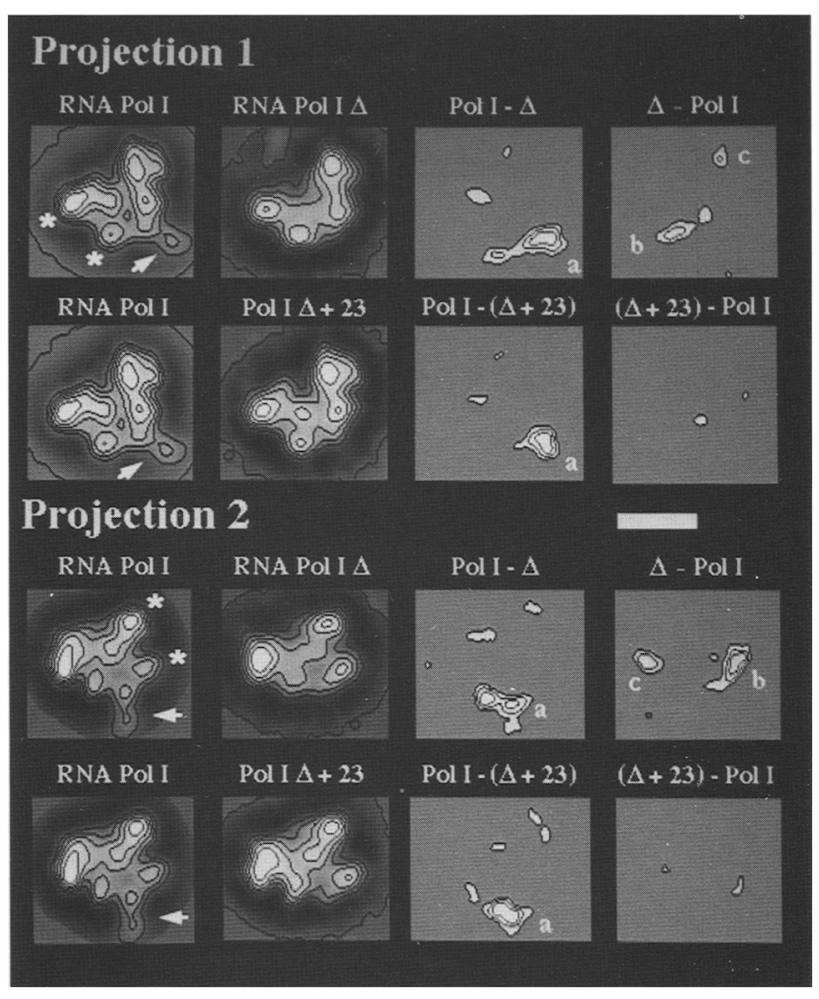

Figure 6. Comparison of native RNA Pol I with mutant complexes. Two characteristic RNA polymerase monomer views (projections 1 and 2 ) were obtained upon averaging aligned images of monomeric enzymes. The stain-excluding protein densities are represented in white and are outlined by contours of equal density. The first column shows native RNA polymerase views [RNA Pol I; number of analyzed images $(n=916)$ ], whereas the RNA Pol I $\Delta\{n=1351)$ or the RNA Pol I $\Delta+23$ $(n=789)$ view is shown in the second column. The difference images shown in the third column correspond to protein densities absent in both mutant enzymes. The disappearence of the elongated stalk (arrow) is apparent on the mutant enzyme views and corresponds to density $a$ in the difference maps. The difference images shown in the fourth column correspond to protein densities present in RNA Pol I $\Delta$ but not in the native enzyme (rows 1 and 3 ) and represent mainly a shortening of the distance between the two asterisks. This difference is absent when subunit $\mathrm{ABC} 23$ is added to RNA Pol I $\Delta$ (rows 2 and 4). Bar, $8.5 \mathrm{~nm}$.

the end of a groove. This difference indicated that in RNA Pol I $\Delta$, a protein density located between a and b was displaced toward b or that the distance between two internal protein densities (marked by asterisks in Fig. 6) was shortened by about $8 \AA$. A similar negative density was observed in the apical region of the enzyme, an area far from densities a and b described previously. Interestingly, this conformational change was reversed upon the addition of subunit $\mathrm{rABC} 23$, as the additional densities $b$ and $c$ were not detected when the average image of RNA Pol I was subtracted from the average image of RNA Pol I $\Delta+23$. To confirm that subunit ABC23 was localized within or close to density a, images of RNA polymerase dimers labeled with subunit ABC23-specific polyclonal 

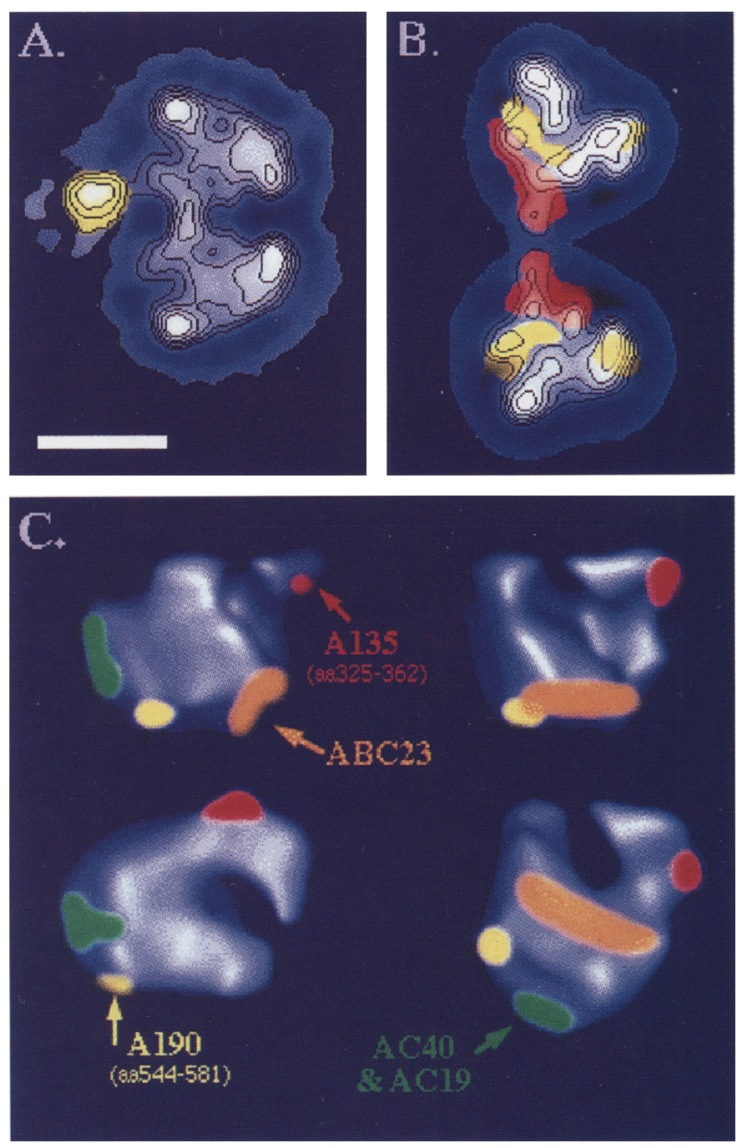

Figure 7. Localization of subunits $\mathrm{ABC} 23$ and A43. (A) Average image of RNA polymerase dimers labeled with anti-ABC23 antibodies were obtained upon analysis of 390 molecular images. The stain-excluding protein densities are outlined by contours of equal density. All of the images were transformed to show binding in the upper molecule; thus, the antibody interaction site is identified by comparing the upper and the lower monomer. The difference image between the labeled and the unlabeled molecule is shown in yellow, where the contours correspond to positive difference thresholds at a significance level of $5 \%$. (B) The positive difference a and the negative differences $\mathrm{b}$ and $\mathrm{c}$ detected in RNA Pol I $\Delta$ (Fig. 6) are represented in the red and yellow areas, on the monomer projections 1 and 2 , respectively. The two monomer views are oriented in such a way as to emphasize their correlation with the dimer projection shown in $A$. The positive differences are found colocalized with the area labeled by the subunit-specific antibodies. (C) Surface representation of the three-dimensional RNA polymerase model showing the position of $\mathrm{ABC} 23$ in orange. Subunit positions determined previously are also indicated (Klinger et al. 1996). Because the antibody interaction site was determined by a single view of the enzyme, the localization of the $\mathrm{ABC} 23$ subunit is not resolved in the viewing direction. Therefore, the orange label for the $\mathrm{ABC} 23$ subunit has an elongated shape. Bar, $10 \mathrm{~nm}$ in $A$ and $B$ and $6.5 \mathrm{~nm}$ in $C$.

antibodies were recorded and analyzed. The antibody interaction sites were defined accurately on average images of labeled RNA Pol I dimers (Fig. 7A). The binding sites of anti-ABC23 IgG were localized in a region close to the dimerization interface that contained the stalk. The antibody binding sites thus colocalized with region a, the positive difference in density detected when the average image of RNA Pol I $\Delta$ was subtracted from the average image of RNA Pol I (Fig. 7B). When projected on the three-dimensional enzyme model (Schultz et al. 1993) the labeled sites were found at the end of a 3-nmwide groove opposite a finger-like structure that defined a channel (Fig. 7C). Altogether, these data indicate that RNA Pol I $\Delta$ had a different conformation than the native enzyme and that this conformational change was reversed by the addition of subunit $\mathrm{ABC} 23$.

\section{Discussion}

We purified an inactive form of RNA Pol I $\Delta$ lacking subunits $\mathrm{A} 43, \mathrm{ABC} 23$, and $\mathrm{A} 14$ from a yeast strain in which the RPA14 gene was deleted. Because the genes encoding subunits $\mathrm{A} 43$ and $\mathrm{ABC} 23$ are essential (Woychik et al. 1990; Thuriaux et al. 1995), we assume that in the mutant strain, RNA Pol I contained these two essential subunits but they were lost during the purification of the enzyme. Addition of $\mathrm{rABC} 23$ to purified RNA Pol I $\Delta$ restored its activity and the maximal reactivation was obtained for a molar ratio of RNA Pol I $\Delta$ to rABC23 of $1: 1$. Furthermore, we demonstrated that rABC23 is bound stably and stoichiometrically to RNA Pol I $\Delta$ and that the reassociation process is rapid and causes a large conformational change in the enzyme detectable by electron miscroscopy. Reactivation of RNA Pol I $\Delta$ with purified $\mathrm{rABC} 23$ expressed in $E$. coli was identical to that obtained with the yeast recombinant subunit (data not shown), suggesting that the phosphorylation of ABC23 (Bell et al. 1976; Valenzuela et al. 1976; Bréant et al. 1983al is not essential for reassociation with RNA Pol I $\Delta$ and for the partial activation of the enzyme. The reason for the incomplete restoration of RNA polymerase activity is unclear. One possibility is that $\mathrm{ABC} 23$ alone might be able to reactivate RNA Pol I $\Delta$ fully. In this model the incomplete reactivation $(20 \%-50 \%)$ of wildtype activity could be explained by the destabilization of a fraction of RNA Pol I $\Delta$ molecules during purification and storage. Alternatively, A43 and/or A14 might be required for complete restoration of enzyme activity. Preliminary reconstitution experiments with rA43 and rA14 subunits expressed in yeast suggested that the latter hypothesis is not verified.

Because ABC23 was strictly required for the transcriptional activity of RNA Pol I, it was interesting to characterize the role of this subunit. RNA Pol I $\Delta$ was found to be inactive when acid-precipitable transcripts were measured as well as in transcriptional conditions where RNA Pol I catalyzed the formation of a single phosphodiester bond. Therefore, RNA Pol I $\Delta$ is affected at an early transcription step, required for phosphodiester bond formation.

Previous results (Bréant et al. 1983b; Huet et al. 1985b) suggested that the $\mathrm{ABC} 23$ subunit might be involved in the binding of the enzyme to DNA. Our results obtained by a gel-shift retardation assay and by SPR do not support 
this hypothesis. The immunoelectron microscopy data (Figs. 6 and 7) showed consistently that subunit $\mathrm{ABC} 23$ was located close to the groove that constitutes a putative DNA-binding site at the end opposite the channel. Our results could not discriminate whether this subunit was located outside or within the groove, as the dimers are preferentially oriented upon antibody binding. Nevertheless, the close proximity of the $\mathrm{ABC} 23$ subunit to the groove, that is, to the DNA path along the enzyme, could explain why the RNA polymerase is less accessible to anti-ABC23 antibodies when the enzyme interacts with the template. This effect could be explained by a steric hindrance rather than a true interaction of $\mathrm{ABC} 23$ with DNA. Assuming that $\mathrm{ABC} 23$ is not involved in DNA binding and/or recognition, it remains possible that RNA Pol I $\Delta$ is affected in nucleotide binding, in DNA opening, or in the catalysis of the phosphodiester bond.

The first hypothesis has not been investigated but seems rather unlikely, as the initiator nucleotide binding site has been mapped on the second largest subunit of the enzyme (Riva et al. 1987). Transcription experiments performed with single-stranded DNA as template suggest that DNA opening was not impaired (data not shown). Thus, RNA Pol I $\Delta$ is likely affected in the catalysis reaction itself. Because $\mathrm{ABC} 23$ binding to RNA Pol I $\Delta$ activated the enzyme, either this subunit is directly involved in the catalytic act or binding of $\mathrm{ABC} 23$ induces a conformational change in the RNA polymerase that makes it competent for transcription. The absence of a subunit homologous to $\mathrm{ABC} 23$ in the bacterial enzyme disfavors a role of $\mathrm{ABC} 23$ in the catalytic reaction itself. Rather, gel shift and electron microscopy experiments support the conformational change hypothesis. Very different DNA-RNA polymerase complexes were obtained with the wild-type enzyme or with RNA Pol I $\Delta$. This difference was not attributable to the three missing subunits, as the association of $\mathrm{ABC} 23$ alone to RNA Pol I $\Delta$ leads to a pattern of DNA-protein complexes similar to that obtained with wild-type enzyme. These data suggest that RNA Pol I $\Delta$ and RNA Pol I have a different conformation that could be reversed by the reassociation of $\mathrm{ABC} 23$.

Conformational changes have already been described for RNA polymerases during the transcription cycle. Comparison of the crystallographic structure of the $E$. coli-initiating enzyme (holoenzyme) and elongating enzyme (core) indicated that their structures are distinct (Polyakov et al. 1995). This structural modification is thought to play a role in enzyme processivity, similarly to T7 RNA polymerase (Sousa et al. 1994). Additional structural transitions are also predicted by the inchworm model of RNA polymerase elongation (Krummel and Chamberlin 1992). Finally, a conformational change in a protein complex attributable to the fixation of a subunit has been described for the $E$. coli RNA polymerase: Binding of the $\sigma^{70}$ subunit to the core enzyme induces a change of conformation of subunits $\beta$ and $\beta^{\prime}$ (Greiner et al. 1996).

Comparative studies of the low resolution structure of
RNA Pol I, RNA Pol I $\Delta$, and RNA Pol I $\Delta+23$ by electron microscopy brought additional evidence for a conformational change induced by $\mathrm{ABC} 23$. They indicate that the quaternary structures of RNA Pol I and RNA Pol I $\Delta$ differ primarily in three regions. Two differences disappeared completely upon reassociation of $\mathrm{ABC} 23$ to RNA Pol I $\Delta$, despite the fact that the binding site of this subunit within the complex is located outside of these regions, and this binding gives rise to a structure similar to that of the wild-type enzyme. Altogether, these data indicate that the binding of $\mathrm{ABC} 23$ to RNA Pol I $\Delta$ results in a conformational change that is absolutely required for enzyme activity. This conformational role is somewhat different from that proposed by Nouraini and coworkers (1996), who showed by genetic analysis of $\mathrm{ABC} 23$ mutants that this subunit is essential for RNA $\mathrm{Pol}$ I and Pol II assembly. In conclusion, our results demonstrate that the $A B C 23$ subunit is required for the structural and functional integrity of RNA Pol I and thus should be considered as part of the RNA Pol I core enzyme (defined as the minimum Pol I subassembly competent for nonspecific transcription). Because $A B C 23$ is shared by the three forms of enzyme, RNA Pol I, Pol II, and Pol III, our results suggest strongly that $\mathrm{ABC} 23$ belongs to the eukaryotic core enzyme; but this proposal remains to be demonstrated for RNA Pol II and III. Alternatively, we cannot formally exclude the possibility that $\mathrm{ABC} 23$ is not a core enzyme subunit but, rather, a regulatory subunit that relieves the inhibitory effect of one or several non-core subunits present in RNA Pol I $\Delta$. This interpretation seems rather unlikely, but identification of the minimal subunit content of the eukaryotic core enzyme will ultimately require the in vitro reconstitution of an active enzyme from purified or recombinant subunits.

Besides these roles, $\mathrm{ABC} 23$ could have additional functions that are specific to transcription by the three different forms of RNA polymerase. The eubacterial RNA polymerase $\alpha$ subunit is a paradigm for this type of dual functionality in that it is involved in RNA polymerase assembly and interaction with activator proteins (Ishihama 1993; Busby and Ebright 1994).

\section{Materials and methods}

\section{Purification of RNA POI I and RNA POI I $\triangle$}

RNA Pol I was purified as described by Riva et al. (1982). RNA Pol I $\Delta$ was purified by the same procedure, with the following modifications. Crude extract prepared from the yeast strain rpa14::URA3 (50 grams) was chromatographed in batch on phosphocellulose (Whatman P11) in BI buffer $(20 \mathrm{~mm}$ Tris- $\mathrm{HCl}$ at $\mathrm{pH} 8.0,0.5 \mathrm{~mm}$ EDTA, $1 \mathrm{~mm} \beta$-mercaptoethanol, $10 \%$ glycerol) containing $50 \mathrm{~mm}$ ammonium sulfate. Proteins were eluted with BI containing $400 \mathrm{~mm}$ ammonium sulfate. The eluate was diluted with BI to an ionic strength of $250 \mathrm{~mm}$ ammonium sulfate and then loaded on a Heparin Hyper D (BioSepra) column $\left(1 \mathrm{~cm}^{2} \times 2.5 \mathrm{~cm}\right)$ at a flow rate of $1 \mathrm{ml} / \mathrm{min}$. Proteins were eluted by a linear gradient from 250 to $800 \mathrm{~mm}$ ammonium sulfate in BI $(55 \mathrm{ml})$ at a flow rate of $1 \mathrm{ml} / \mathrm{min}$. As RNA Pol I $\Delta$ is inactive, fractions containing the enzyme were selected by Western blot analysis with anti-RNA Pol I antibodies, pooled, 
and dialyzed against BI containing $50 \mathrm{~mm}$ ammonium sulfate. This fraction was loaded on a Q Hyper D column $(1.7 \mathrm{ml}$, BioSepra) that was developed with a linear gradient from 50 to $400 \mathrm{~mm}$ ammonium sulfate in $35 \mathrm{ml}$ of $\mathrm{BI}$ at a flow rate of 1 $\mathrm{ml} / \mathrm{min}$. The RNA Pol I $\Delta$-containing fractions were pooled, concentrated to a volume of $\sim 100-200 \mu \mathrm{l}$ by ultrafiltration (Centricon-100, Amicon) and loaded on a $10 \%-30 \%$ glycerol gradient in $20 \mathrm{~mm}$ Tris- $\mathrm{HCl}(\mathrm{pH} 8.0), 0.5 \mathrm{~mm}$ EDTA, $1 \mathrm{~mm} \beta$-mercaptoethanol, and $150 \mathrm{~mm}$ ammonium sulfate. They were centrifuged in a SW41 rotor (Beckmann), at $40,000 \mathrm{rpm}$ and $4^{\circ} \mathrm{C}$ for $18 \mathrm{hr}$. Fractions containing RNA Pol I $\Delta$ were stored at $-80^{\circ} \mathrm{C}$.

\section{Construction of His-tagged RPB6}

The RPB 6 allele tagged at its amino terminus with the HA epitope of influenza virus in pRP611 (Woychik et al. 1990) was modified at its amino and carboxyl terminus by PCR-mediated mutagenesis. At the amino terminus, the sequence of the restriction enzyme HindIII followed by the ATG start codon and the coding sequence of six histidines was fused in-frame with the coding sequence of the epitope-tagged RPB6 DNA in pRP611. At the carboxyl terminus, the sequence of the restriction enzyme $X b a I$ was introduced at the end of the RPB6-coding sequence. The resulting HindIII-XbaI fragment was then cloned downstream of the GAL1 promoter (pGAL1) in the yeast expression vector pYES2 ( $2 \mu$ URA3) (Invitrogen) digested with HindIII and $X b a \mathrm{I}$, resulting in plasmid p31. Plasmid p31 was introduced into the yeast strain YGSV-003 (Shpakovski et al. 1995) by plasmid shuffling, resulting in strain LS174.

\section{Expression and purification of $r A B C 23$}

LS174 cells expressing the His6-HA-tagged RPB6 gene under the control of the pGAL1 were grown in YPGal medium $(2 \%$ yeast extract, $1 \%$ Bacto-Peptone, $2 \%$ galactose) and harvested in late log phase. Crude extract from 2.5 grams of cells, prepared as described by Riva et al. (1982), was chromatographed on phosphocellulose (Whatman $\mathrm{P} 11)$ in buffer $\mathrm{I}(20 \mathrm{~mm}$ Tris- $\mathrm{HCl}$ at $\mathrm{pH}$ $8,10 \mathrm{~mm} \beta$-mercaptoethanol, $0.5 \mathrm{~mm}$ EDTA, $10 \%$ glycerol/ containing $150 \mathrm{~mm}$ ammonium sulfate. Proteins $(150 \mathrm{mg})$ in the flowthrough, which contained the free $\mathrm{rABC} 23$ subunit, were loaded directly onto a 5-ml HiTrapNi column (Pharmacia) equilibrated in buffer II $(20 \mathrm{~mm}$ HEPES-NaOH at $\mathrm{pH} 7.5,100$ $\mathrm{mm} \mathrm{NaCl}, 10 \%$ glycerol) containing $40 \mathrm{~mm}$ imidazole. The column was washed with buffer II containing $50 \mathrm{~mm}$ imidazole, and proteins were eluted by a linear gradient from 50 to $270 \mathrm{mM}$ imidazole in $67.5 \mathrm{ml}$ of buffer II at a flow rate of $0.5 \mathrm{ml} / \mathrm{min}$. Fractions containing $\mathrm{rABC} 23$ as detected by Western blotting analysis with anti-ABC23 antibodies were pooled, dialyzed against buffer I, and loaded onto a MonoQ (SMART) column equilibrated in buffer I. The column was washed with buffer I, and proteins were eluted by a linear gradient from $0 \mathrm{~mm}$ to $1 \mathrm{M}$ ammonium sulfate in $1.5 \mathrm{ml}$ at a flow rate of $150 \mu \mathrm{l} / \mathrm{min}$. The purity of the rABC23 subunit was checked by electrophoresis on a 13\% SDS-polyacrylamide gel (Laemmli 1970) and silver staining (Blum et al. 1987). From 2.5 grams of wet cells, $160 \mu \mathrm{g}$ of homogenous $\mathrm{AABC} 23$ subunit was recovered.

\section{Reconstitution of RNA Pol I $\Delta$ with rABC23}

Forty micrograms of RNA Pol I $\Delta$ were incubated with a twofold molar excess ( $4 \mu \mathrm{g}$ ) of $\mathrm{rABC} 23$ in $50 \mu \mathrm{l}$ of reconstitution buffer $\mathrm{RB}(50 \mathrm{mM}$ Tris- $\mathrm{HCl}$ at $\mathrm{pH} 8.0,200 \mathrm{~mm}$ potassium acetate, 0.5 mM EDTA, 1 mM DTT, $10 \mu \mathrm{m}$ zinc acetate, $20 \%$ glycerol) for 20 min to $1 \mathrm{hr}$ at $15^{\circ} \mathrm{C}$. Reconstituted RNA Pol I $\Delta+23$ was purified by gel filtration at a flow rate of $40 \mu \mathrm{l} / \mathrm{min}$ on a Superose 12
PC SMART column (Pharmacia) equilibrated in BI buffer containing $100 \mathrm{~mm}$ ammonium sulfate. Fractions of $40 \mu \mathrm{l}$ were collected.

\section{Construction of the dC-tailed template}

Equimolar amounts of two complementary oligonucleotides, A and $B$ (see below), with lengths of 37 and 45 nucleotides, respectively, were mixed in TE buffer $(20 \mathrm{mM}$ Tris- $\mathrm{HCl}$ at $\mathrm{pH} 7.8,1$ mM EDTA $\mid$, heated at $90^{\circ} \mathrm{C}$ for $5 \mathrm{~min}$, and cooled down to $22^{\circ} \mathrm{C}$ in $2 \mathrm{hr}$. Single-strand oligonucleotides were separated from the double-stranded dC-tailed template by gel permeation chromatography on a Superdex 75 PC SMART column (Pharmacia). Oligonucleotide sequences were A, 5' -CTCGTGCTGCGGTCGTGTAAAAAGCAGCAAGCCAGGC-3', and B, 5'-GCCTGGCTTGCTGCTTTTTACACGACCGCAGCACGAGCCCCCCCC-3'.

\section{RNA polymerase transcription assay}

RNA polymerase was assayed in $40 \mu$ of transcription buffer (TB) (20 mM HEPES-KOH at pH 7.5, $50 \mathrm{~mm} \mathrm{KCl,} 5 \mathrm{mM} \mathrm{MgCl}_{2}$, $1 \mathrm{~mm}$ DTT, $5 \%$ glycerol) containing $2 \mu \mathrm{g}$ of poly[d(A-T)], $0.5 \mathrm{~mm}$ ATP, $0.1 \mathrm{~mm}$ UTP, and $0.2 \mu \mathrm{Ci}$ of $\left[\alpha^{-32} \mathrm{P}\right] \mathrm{UTP}(20-60 \mathrm{cpm} /$ pmole). After $30 \mathrm{~min}$ of incubation at $30^{\circ} \mathrm{C}$, the reaction was stopped by the addition of $2 \mathrm{ml}$ of ice-cold $5 \%$ trichloroacetic acid (TCA) (wt/vol). Acid-insoluble radioactivity was collected on a Millipore filter HAWP $025(0.45 \mu \mathrm{m})$ and washed with $\sim 30$ $\mathrm{ml}$ of cold $5 \%$ TCA. The filter was then dried and counted with $5 \mathrm{ml}$ of scintillation fluid.

\section{Trinucleotide synthesis}

RNA polymerases were incubated in $15 \mu$ of TB containing 2 pmoles of dC-tailed template, $0.66 \mathrm{~mm} \mathrm{GpG}, 0.05 \mathrm{~mm} \mathrm{CTP}, 10$ $\mu \mathrm{Ci}$ of $\left[\alpha-{ }^{32} \mathrm{P}\right] \mathrm{CTP}$ for $30 \mathrm{~min}$ at $30^{\circ} \mathrm{C}$. RNA Pol I was preincubated with the template and $\mathrm{GpG}$ for $10 \mathrm{~min}$ at $22^{\circ} \mathrm{C}$ before addition of the nucleotides. The transcripts were separated by electrophoresis on a $20 \%$ polyacrylamide gel in the presence of $6 \mathrm{M}$ urea in TBE $(90 \mathrm{~mm}$ Tris-borate, $2 \mathrm{~mm}$ EDTA). The gel was dried, and radioactivity was detected and quantified with a PhosphorImager (Molecular Dynamics).

\section{Gel retardation assay}

RNA Pol I ( $1 \mu \mathrm{g})$ was complexed with the dC-tailed template in a mixture containing 1 pmole of the ${ }^{32} \mathrm{P}$-end-labeled dC-tailed template $(10,000 \mathrm{cpm})$ in $40 \mu \mathrm{l}$ of TB. After $20 \mathrm{~min}$ of incubation at $22^{\circ} \mathrm{C}$ the RNA Pol I-DNA complexes were separated from free DNA by gel electrophoresis on a $5 \%$ polyacrylamide gel as described previously (Huet et al. 1985a).

\section{$S P R$}

RNA polymerase was covalently bound to a CM5 sensor chip (Pharmacia) following the method of Johnsson et al. (1991) at a flow rate of $20 \mu \mathrm{l} / \mathrm{min}$. The biotinylated $\mathrm{dC}$-tailed template was immobilized on a sensor chip (SA5; Pharmacia). The binding reactions and washing steps were performed in buffer HBS $\mid 10$ mM HEPES-KOH at pH 7.4, $150 \mathrm{~mm} \mathrm{NaCl}, 3.4 \mathrm{mM}$ EDTA, $0.005 \%$ Surfactant $\mathrm{P} 20$ ). Association rates were measured on a BIAcore 2000 apparatus (Pharmacia) from binding profiles obtained by injecting RNA Pol I or RNA Pol I $\Delta$ at six different concentrations $(1.0,2.5,5.0,10.0,15.0$ and $20 \mathrm{nM})$ on the immobilized dC-tailed template. Both association and dissociation 
constants were determined using Pharmacia Kinetics Evaluation software to solve the rate equations (Karlsson et al. 1991).

\section{Specimen preparation for electron microscopy and image processing}

Immune complexes formed in solution and in equimolar enzyme to antibody ratios were diluted to a concentration of 20 $30 \mathrm{mg} / \mathrm{ml}$ in buffer $\mathrm{A}(20 \mathrm{~mm}$ Tris- $\mathrm{HCl}$ at $\mathrm{pH} 7.4,50 \mathrm{~mm}$ ammonium sulfate, $5 \mathrm{~mm} \mathrm{MgCl}_{2}, 2 \mathrm{~mm} \mathrm{DTT}, 20 \%$ glycerol). Ten microliters of this preparation was placed on a 10 -nm-thick carbon film treated previously with a glow discharge in air. After 2 min of adsorption, the grid was stained negatively with a $2 \%$ uranyl acetate solution. When the native RNA polymerase was compared to the mutant or reconstituted enzyme, the three samples were dialyzed against buffer A and prepared simultaneously for electron microscopy as described for immune complexes.

The images were formed on a Vacuum Generator HB5 Scanning Transmission Electron Microscope (STEM) operating at $100 \mathrm{kV}$ and analyzed as described (Klinger et al. 1996). Because of the absence of phase contrast in the STEM annular dark-field signal, the contrast transfer function of the microscope is comparable between different data sets in the selected resolution range. Density differences between average images were normalized by the square root of the sum of the variances of the averages, and the normalized differences reached thresholds at 1.96 , which represents the $5 \%$ significance level if normality is assumed (Schultz et al. 1990).

\section{Acknowledgments}

We thank V. Mallouh for support in image processing and J.C. Homo for help with electron microscopes. We also thank E. Favry for his efficient participation in purification of rABC23 subunit and RNA Pol I $\Delta$ enzyme, J.M. Buhler for the construction of the plasmid p31, E. Edwards for providing us rABC23 expressed in E. coli, and V. Hanin for her help in the SPR experiments. We are very grateful to $C$. Mann for a critical reading of the manuscript. M. Lanzendörfer was supported by a European Molecular Biology Organization long-term fellowship. This work was supported by a Human Frontier Science Program Organization grant.

The publication costs of this article were defrayed in part by payment of page charges. This article must therefore be hereby marked "advertisement" in accordance with 18 USC section 1734 solely to indicate this fact.

\section{References}

Archambault, J., K.T. Schappert, and J.D. Friesen. 1990. A suppressor of an RNA polymerase II mutation of Saccharomyces cerevisiae encodes a subunit common to RNA polymerases I, II, and III. Mol. Cell. Biol. 10: 6123-6131.

Bell, G.I., P. Valenzuela, and W.J. Rutter. 1976. Phosphorylation of yeast RNA polymerases. Nature 261: 429-431.

- 1977. Phosphorylation of yeast DNA-dependent RNA polymerases in vivo and in vitro. Isolation of enzymes and identification of phosphorylated subunits. I. Biol. Chem. 252: 3082-3091.

Blum, H., H. Beier, and H.J. Gross. 1987. Improved silver staining of plant proteins, RNA and DNA in polyacrylamide gels. Electrophoresis 8: 93-99.

Brëant, B., J.-M. Buhler, A. Sentenac, and P. Fromageot. 1983a. On the phosphorylation of yeast RNA polymerases A and B. Eur. J. Biochem. 130: 247-251.
Brëant, B., J. Huet, A. Sentenac, and P. Fromageot. 1983b. Analysis of yeast RNA polymerases with subunit-specific antibodies. J. Biol. Chem. 258: 11968-11973.

Buhler, J.-M., F. Iborra, A. Sentenac, and P. Fromageot. 1976a. The presence of phosphorylated subunits in yeast RNA polymerases A and B. FEBS Lett. 71: 37-41.

- 1976 b. Structural studies on yeast RNA polymerases. Existence of common subunits in RNA polymerases $A(I)$ and B(II). J. Biol. Chem. 251: 1712-1717.

Buhler, J.-M., J. Huet, K.E. Davies, A. Sentenac, and P. Fromageot. 1980. Immunological studies of yeast nuclear RNA polymerases at the subunit level. J. Biol. Chem. 255: 99499954.

Bult, C., O. White, G.J. Olsen, L. Zhou, R.D. Fleischmann, G.G. Sutton, J.A. Blake, L.M. FitzGerald, R.A. Clayton, J.D. Gocayne, et al. 1996. Complete genome sequence of the methanogenic archaeon Methanococcus jannaschii. Science 273: 1058-1073.

Busby, S. and R. Ebright. 1994. Promoter structure, promoter recognition, and transcription activation in prokaryotes. Cell 79: 743-746.

Carles, C., I. Treich, F. Bouet, M. Riva, and A. Sentenac. 1991. Two additional common subunits, $A B C 10 \alpha$ and $A B C 10 \beta$, are shared by yeast RNA polymerases. I. Biol. Chem. 266: 24092-24096.

Dequard-Chablat, M., M. Riva, C. Carles, and A. Sentenac. 1991. RPC19, the gene for a subunit common to yeast RNA polymerase A (I) and C (III). J. Biol. Chem. 266: 15300-15307.

Greiner, D.P., K.A. Hughes, A.H. Gunasekera, and C.F. Meares. 1996. Binding of the $\sigma^{70}$ protein to the core subunits of Escherichia coli RNA polymerase, studied by iron-EDTA protein footprinting. Proc. Nat1. Acad. Sci. 93: 71-75.

Huet, J., A. Sentenac, and P. Fromageot. 1982. Spot-immunodetection of conserved determinants in eukaryotic RNA polymerases. Study with antibodies to yeast RNA polymerases subunits. J. Biol. Chem. 257: 2613-2618.

Huet, J., P. Cottrelle, M. Cool, M.L. Vignais, D. Thiele, C. Marck, J.-M. Buhler, A. Sentenac, and P. Fromageot. 1985a. A general upstream binding factor for genes of the yeast translational apparatus. EMBO J. 4: 3539-3547.

Huet, I., M. Riva, A. Sentenac, and P. Fromageot. 1985b. Yeast RNA polymerase $C$ and its subunits. Specific antibodies as structural and functional probes. J. Biol. Chem. 260: 1530415310.

Ishihama, A. 1993. Protein-protein communication within the transcription apparatus. J. Bacteriol. 175: 2483-2489.

Johnsson, B., S. Löfas, and G. Lindquist. 1991. Immobilization of proteins to a carboxymethyldextran-modified gold surface for biospecific interaction analysis in surface plasmon resonance sensors. Anal. Biochem. 198: 268-277.

Karlsson, R., A. Michaelsson, and A. Mattson. 1991. Kinetic analysis of monoclonal antibody-antigen interactions with a new biosensor based analytical system. I. Immunol. Methods 145: 229-240.

Klinger, C., J. Huet, D. Song, G. Petersen, M. Riva, A. Sentenac, E.K.F. Bautz, P. Oudet, and P. Schultz. 1996. Localization of yeast RNA polymerase I core subunits by immunoelectron microscopy. EMBO J. 15: 4643-4653.

Krummel, B. and M.J. Chamberlin. 1992. Structural analysis of ternary complexes of Escherichia coli RNA polymerase. Deoxyribonuclease I footprinting of defined complexes. I. Mol. Biol. 225: 239-250.

Laemmli, U.K. 1970. Cleavage of structural proteins during the assembly of the head of bacteriophage T4. Nature 227: 680685.

Langer, D., J. Hain, P. Thuriaux, and W. Zillig. 1995. Transcrip- 
tion in archaea: Similarity to that in eucarya. Proc. Natl. Acad. Sci. 92: 5768-5772.

Lanzendörfer, M., D. Langer, J. Hain, H.-P. Klenk, I. Holz, I. Arnold-Ammer, and W. Zillig. 1994. Structure and function of the DNA-dependent RNA polymerase of Sulfolobus. Syst. Appl. Microbiol. 16: 1241-1250.

Mann, C., J.-M. Buhler, I. Treich, and A. Sentenac. 1987. RPC40, a unique gene for a subunit shared between yeast RNA polymerases A and C. Cell 48: 627-637.

McKune, K., P. Moore, M. Hull, and N. Woychik. 1995. Six human RNA polymerase subunits functionally substitute for their human counterparts. Mol. Cell. Biol. 15: 68956900.

Nouraini, S., J. Archambault, and J.D. Friensen. 1996. Rpo26p, a subunit common to yeast RNA polymerases, is essential for the assembly of RNA polymerases I and II and for the stability of the largest subunits of these enzymes. Mol. Cell. Biol. 16: 5985-5996.

Polyakov, A., E. Severinova, and S.A. Darst. 1995. Three-dimensional structure of E. coli core RNA polymerase: Promotor binding and elongation conformations of the enzyme. Cell 83: 365-373.

Riva, M., J.-M. Buhler, A. Sentenac, P. Fromageot, and D. Hawthorne. 1982. Natural variation in yeast RNA polymerase A. Formation of a mosaic RNA polymerase A in a meiotic seg. regant from an interspecific hybrid. J. Biol. Chem. 257: $4570-4577$.

Riva, M., A.R. Schaffner, A. Sentenac, G.R. Hartmann, A.A. Mustaev, E.F. Zaychikov, and M.A. Grachev. 1987. Active site labeling of the RNA polymerase A, B, and C from yeast. J. Biol. Chem. 262: 14377-14380.

Sawadogo, M., J. Huet, and P. Fromageot. 1980. Similar binding site for P37 factor on yeast RNA polymerases A and B. Biochem. Biophys. Res. Commun. 96: 258-264.

Schultz, P., P. Nobelis, P. Colin, M. Louys, J. Huet, A. Sentenac, and P. Oudet. 1990. Electron microscopic study of yeast RNA polymerase A: analysis of single molecular images. Chromosoma 99: 196-204.

Schultz, P., H. Celia, M. Riva, A. Sentenac, and P. Oudet. 1993. Three-dimensional model of yeast RNA polymerase I determined by electron microscopy of two-dimensional crystals. EMBO I. 12: 2601-2607.

Sentenac, A. 1985. Eukaryotic RNA polymerases. CRC Crit. Rev. Biochem. 18: 31-90.

Shpakovski, G.V., J. Acker, M. Wintzerith, J.F. Lacroix, P. Thuriaux, and M. Vigneron. 1995. Four subunits that are shared by the three classes of RNA polymerase are functionnaly interchangeable between Homo sapiens and Saccharomyces cerevisiae. Mol. Cell. Biol. 15: 4702-4710.

Smid, A., M. Riva, F. Bouet, A. Sentenac, and C. Carles. 1995. The association of three subunits with yeast RNA polymerase is stabilized by A14. J. Biol. Chem. 270: 13534-13540.

Sousa, R., J.P. Rose, and B.C. Wang. 1994. The thumb's knuckle. Flexibility in the thumb subdomain of T7 RNA polymerase. I. Mol. Biol. 244: 6-12.

Tang, H., Y. Kim, K. Severinov, A. Goldfarb, and R.H. Ebright. 1996. Escherichia coli RNA polymerase holoenzyme: Rapid reconstitution from recombinant $\alpha, \beta, \beta^{\prime}$, and $\sigma$ subunits. Methods Enzymol. 273: 130-134.

Thuriaux, P., S. Mariotte, J.M. Buhler, A. Sentenac, L. Vu, B.S. Lee, and M. Nomura. 1995. Gene RPA43 in Saccharomyces cerevisiae encodes an essential subunit of RNA polymerase I. J. Biol. Chem. 270: 24252-24257.

Valenzuela, P., G. Bell, F. Weinberg, and W. Rutter. 1976. Yeast DNA dependent RNA polymerase I, II and III. The existence of subunits common to the three enzymes. Biochem. Bio- phys. Res. Commun. 71: 1319-1325.

Woychik, N.A., S.-M. Liao, P.A. Kolodziej, and R.A. Young. 1990. Subunits shared by eukaryotic nuclear RNA polymerases. Genes \& Dev. 4: 313-323. 


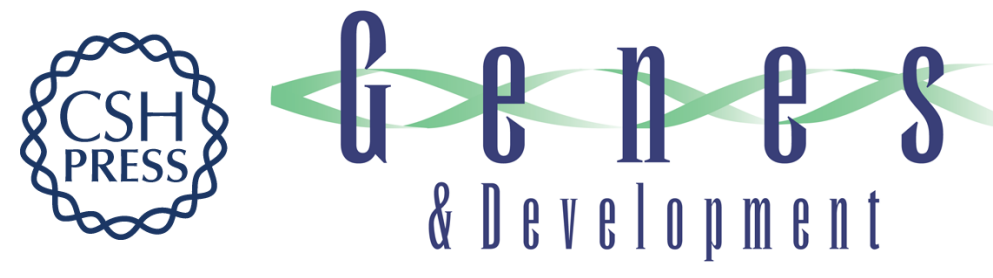

\section{A shared subunit belongs to the eukaryotic core RNA polymerase.}

M Lanzendörfer, A Smid, C Klinger, et al.

Genes Dev. 1997, 11:

Access the most recent version at doi:10.1101/gad.11.8.1037

References This article cites 41 articles, 21 of which can be accessed free at:

http://genesdev.cshlp.org/content/11/8/1037.full.html\#ref-list-1

License

Email Alerting Receive free email alerts when new articles cite this article - sign up in the box at the top Service right corner of the article or click here.

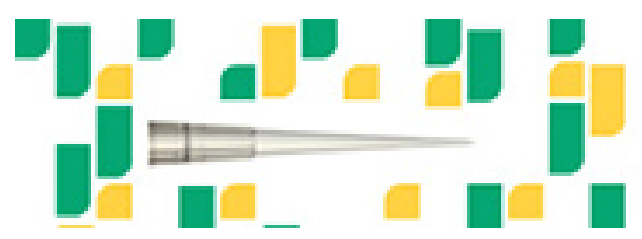

Focused on your science.

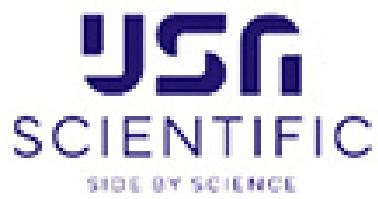

Copyright (c) Cold Spring Harbor Laboratory Press 